\title{
Clinical Significance of Tetrofosmin Extracardiac Uptake During Myocardial Perfusion Imaging
}

\author{
Panagiotis Georgoulias ${ }^{1}$, Varvara Valotassiou ${ }^{1}$, Ioannis Tsougos ${ }^{1}$, \\ George Angelidis ${ }^{1}$ and Nikolaos Demakopoulos ${ }^{2}$ \\ ${ }^{1}$ Department of Nuclear Medicine, University Hospital of Larissa, \\ ${ }^{2}$ Department of Nuclear Medicine, NIMTS Hospital,
}

Greece

\section{Introduction}

Coronary artery disease (CAD) is a major cause of mortality and morbidity and its management consumes a large proportion of national healthcare budgets (Underwood et al., 2004). It has been estimated that approximately twenty diseases account for over $80 \%$ of all the deaths in the world (Satra et al., 2011). Specifically, atherosclerosis which occurs in the coronary arteries as the underlying defect responsible for CAD accounts for nearly half of these deaths. Although CAD treatment protocols are improving, its prevalence has increased. New imaging technologies have added to the immediate costs of investigation but they also have the potential to reduce overall costs, by virtue of their greater diagnostic and prognostic accuracy. This allows a more informed selection of therapy, which in turn can lead to a better clinical outcome (Underwood et al., 2004).

Myocardial perfusion scintigraphy (MPS) was developed in the 1970s and has been used increasingly in clinical cardiology since the 1980s (Underwood et al., 2004). Technical developments that have fuelled this recent increase are single-photon emission tomographic computed imaging (SPECT), pharmacological stress and ECG-gated imaging (Underwood et al., 2004). Nowadays, MPS comprises the only widely available method of assessing myocardial perfusion directly and many previously published reports support its evidence in the diagnosis of myocardial ischaemia and necrosis (Satra et al., 2011). Moreover, the prognostic value of this method for patients' risk stratification has already been extensively reported, with an incremental prognostic value after clinical assessment, exercise electrocardiography and even above coronary angiography (Satra et al., 2011). Thus, MPS is an established imaging technique that is already an integral part of the management of CAD (diagnosis, prognostication, selection for revascularization and assessment of acute coronary syndromes) and is included in a number of professional guidelines (Underwood et al., 2004).

\section{SPECT myocardial perfusion imaging agents}

MPS involves intravenous injection of small amounts of a radioactive tracer, usually during some form of cardiovascular stress. The three commercially available tracers are thallium201 thallous chloride (Tl-201), technetium-99m (Tc-99m) 2-methoxy-isobutyl-isonitrile 
(MIBI) and technetium-99m 1,2-bis[bis(2-ethoxyethyl) phosphino] ethane (tetrofosmin). These are avidly extracted by cardiac myocytes and hence their initial myocardial distribution reflects a combination of the distribution of myocytes and perfusion. Comparison of images following stress and rest injections of tracer (or following redistribution for thallium) allows myocardial viability and perfusion to be assessed independently (Underwood et al., 2004). Tl-201 is a good tracer of myocardial perfusion and it has been used clinically for more than two decades (Hesse et al., 2005). It is administered intravenously as thallous chloride and the usual activity is $80 \mathrm{MBq}$. It does, however, have limitations:

i. $\quad$ Relatively long physical half-life: high radiation burden for the patient $(80 \mathrm{MBq}$ delivers an effective dose of approximately $18 \mathrm{mSv}$ ).

ii. Relatively low injected activity: low signal-to-noise ratio; images can be suboptimal (obese patients) and low count levels impair high-quality ECG-gated SPECT studies.

iii. Relatively low energy emission: low-resolution images and significant attenuation by soft tissue.

Tc-99m compounds do not have these limitations, which has encouraged the development and increasing use of such tracers, even if the physiological properties (somewhat lower fractional myocardial tracer uptake, in particular during high coronary flow values) of both Tc-99m labeled tracers are inferior to those of Tl-201 (Hesse et al., 2005). Two Tc-99m labeled perfusion tracers are currently available commercially: Tc-2-methoxyisobutylisonitrile (sestamibi) and Tc-1,2-bis[bis(2-ethoxyethyl) phosphino] ethane (tetrofosmin). Tc-99m sestamibi is a cationic complex which diffuses passively through the capillary and cell membrane, although less readily than Tl-201, resulting in lower immediate extraction. Within the cell it is localized in the mitochondria, where it is trapped ( $\mathrm{Li}$ et al., 1990), and retention is based on intact mitochondria, reflecting viable myocytes. Elimination of the radiotracer occurs mostly through the kidneys and the hepatobiliary system. Tetrofosmin comprises an interesting alternative radiotracer for myocardial perfusion scanning, as it combines the exceptional physical properties of Tc-99m with easy and fast preparation. This compound is also cleared rapidly from the blood and its myocardial uptake is rather similar to that of sestamibi (Jain et al., 1993), with approximately $1.2 \%$ of the administered dose being taken up by the myocardium. The exact mechanism of uptake is unknown, but it is supposed to be similar to that of sestamibi. Elimination of the radiotracer occurs mostly through the kidneys and the hepatobiliary system, and the hepatic clearance is slightly more rapid than in the case of sestamibi (Münch et al., 1997). For both Tc-99m labeled tracers splanchnic uptake and excretion are markedly higher than for Tl-201, which may occasionally complicate interpretation of the inferior wall perfusion. The tracer molecules taken up by the cardiac myocytes remain within the cells: usually two visits on two different days are necessary to obtain optimal stress and rest images (Anagnostopoulos et al., 2003; Hesse et al., 2005).

After intravenous injection, Tc-99m labeled radiopharmaceuticals are distributed within the myocardium according to myocardial perfusion and viability. Unlike Tl-201, they have little (sestamibi) or almost no redistribution (tetrofosmin) and so separate injections are required for stress and resting studies. The higher energy of Tc-99m generally leads to better quality images (because of less attenuation and scatter). Moreover, the short half-life of Tc-99m permits much higher activities to be administered, giving better counting statistics and thus allowing performance of left ventricular (LV) ECG gating or first-pass imaging, which provides additional functional information. The diagnostic reference level for tomography is 
a total of $1000 \mathrm{MBq}$ for a one-day protocol (normally divided as $250 \mathrm{MBq}$ and $750 \mathrm{MBq}$ ), or $400 \mathrm{MBq}$ for each study of a two-day protocol. Higher activities can be considered on an individual basis by the practitioner, for instance in obese patients (Anagnostopoulos et al., 2003; Hesse et al., 2005).

\section{Clinical evaluation of MPS}

Many studies have evaluated the diagnostic accuracy of MPS for the detection of coronary heart disease, but they are of variable size and quality. There is a wide range of values reported for sensitivity and specificity that tend to overlap between different tests, although there have been studies comparing these different protocols in a head-to-head fashion. In the largest single study of 2,560 patients randomized to each of the three tracers and using mainly adenosine stress (the ROBUST study), overall sensitivity in the subset of patients undergoing angiography was $91 \%$, specificity $87 \%$ and normalcy rate $89 \%$, with no significant difference between the three tracers (Kapur et al., 2002). However, image quality was superior for the studies acquired with the Tc-99m-based agents, most likely due in part to the lower energy of Tl201. In contrast, there is generally good agreement between Tc-99m sestamibi and Tc-99m tetrofosmin in identifying myocardial ischaemia (Russell \& Zaret, 2006). In one of our previous studies using Tc-99m tetrofosmin as the radiotracer, we have found a good segmental agreement between tetrofosmin scintigram and coronary angiography. The sensitivity, specificity, positive predictive value and negative predictive value ranged between $72.2-91.1 \%, 80.0-88.2 \%, 76.4$ $88.5 \%$ and $83.3-85.7 \%$ respectively, depending on the obstructed vessel (Georgoulias et al., 1996).

The power of myocardial perfusion imaging (MPI) for predicting future coronary events has been demonstrated in a large number of high-quality studies and in many thousands of patients. It is perhaps the area of nuclear cardiology where the evidence is most strong (Brown, 1991, 1995, 1996). The most important variables that predict the likelihood of future events are the extent and severity of inducible ischaemia (Ladenheim et al., 1986) but other predictors are increased lung uptake of thallium (Gill et al., 1987), stress-induced ventricular dilatation (Weiss et al., 1987) and left ventricular ejection fraction (Gioia et al., 1996; Johnson et al., 1997). In general, markers of left ventricular dysfunction tend to predict cardiac mortality and inducible ischaemia predicts acute coronary syndromes (Hachamovitch et al., 1998; Sharir et al., 2001). MPS has incremental prognostic value even after clinical assessment, exercise electrocardiography and coronary angiography (Iskandrian et al., 1993; Sharir et al., 1999). In other words, patients who appear to be high risk after coronary angiography can be separated into higher and lower risk groups by MPS. In addition, several studies have indicated that a negative SPECT study confers an excellent prognosis with an annual cardiac event rate of $<1 \%$ for the general population (Geleijnse et al., 1996; Iskander \& Iskandrian, 1998; Machecourt et al., 1994; Marie et al., 1995; Schinkel et al., 2005; Shaw et al., 2003). In the setting of a normal myocardial perfusion study in a low-risk patient, it takes 9 years for the risk of a cardiac event to reach 1\%, suggesting that, in the absence of new symptoms, a repeat perfusion study may not be needed for 3 to 5 years (Russell \& Zaret, 2006). However, this "warranty period" does not appear to be absolute and is affected by clinical and technical factors, including the presence of diabetes or CAD, increasing age and male gender, and the need to perform a pharmacologic stress test rather than an exercise perfusion imaging test, which can increase the annual cardiac event rate in patients with a normal perfusion scan to as high as $1.8 \%$ (Hachamovitch et al., 2003). In 
these high-risk patients with normal myocardial perfusion studies, it may be prudent to perform repeat perfusion imaging on a more frequent basis.

Because of its prognostic power, MPS can be used as the gatekeeper to coronary angiography. Bateman and colleagues showed that referral to coronary angiography after normal, mild to moderately abnormal and severely abnormal perfusion scans was $3.5 \%, 9 \%$ and $60 \%$ respectively (Bateman et al., 1995). Importantly, a policy of selective referral to coronary angiography based upon high-risk findings is defensible, as patients with mild to moderate abnormalities when managed medically have outcomes comparable to those undergoing invasive evaluation and subsequent revascularization (Underwood et al., 2004). Besides, several reports underlie that such a policy can be also cost-effective even if it is more expensive than an alternative test such as the exercise ECG (Underwood et al., 2004). Furthermore, MPS can provide useful information about cardiac risk in patients requiring non-cardiac surgery although these patients are generally at low risk and the predictive value of a normal perfusion study is greater than that of an abnormal study, while the clinical value of MPS using Tc-99m labeled agents (MIBI, tetrofosmin) to assess patients with acute coronary syndrome has been well established (Underwood et al., 2004).

MPS is of proven value to assess patients post revascularization. Information gained from post-intervention myocardial SPECT is important to differentiate patients with angina from those with exo-cardiac chest pain syndromes, to assess peri-intervention myocardial damage/acute vessel closure, to predict-detect restenosis after PCI and graft occlusion/stenosis after CABG surgery, to detect CAD progression in non-revascularized vessels, to assess left ventricular function (gated-SPECT), to evaluate the effects of intervention if required for occupational reasons and to predict patients' long-term prognosis. With respect to detect graft patency, MPS has a $80-96 \%$ sensitivity and $61-88 \%$ specificity, while regarding restenosis after $\mathrm{PCI}$, sensitivity and specificity range between 74$94 \%$ and $67-88 \%$, respectively (Georgoulias et al., 1998, 2008, 2010b). Specifically, using Tc$99 \mathrm{~m}$ tetrofosmin as the radiotracer, we have reported a sensitivity, specificity, positive and negative predictive value of MPI in detecting restenosis of $81.3 \%, 88 \%, 81.3 \%$ and $88 \%$, respectively, whereas for the detection of restenosis in specific vessel, the corresponding values were $81.3 \%, 90 \%, 76.5 \%$ and $89.7 \%$, respectively (Georgoulias et al., 1998, 2008, 2010b).

\section{Increased pulmonary uptake during MPI}

It is generally supported that increased pulmonary uptake of a myocardial perfusion radiotracer reflects increased pulmonary capillary wedge pressure. This finding may be attributed to either ischaemic or non-ischaemic causes (valvular heart disease, cardiomyopathy, and pulmonary disease).

\subsection{TI-201 pulmonary uptake}

A significant number of studies have engaged with the clinical importance of increased thallium (Tl)-201 lung uptake during myocardial perfusion imaging (Gill et al., 1987; Homma et al., 1987; Hurwitz et al., 1992; Kaul et al., 1998; Kurata et al., 1991; Liu et al., 1985; Mahmood et al., 1992). The quantification of lung uptake is mostly estimated using the lung/heart ratio (LHR) of radioactivity (counts/pixel) in two regions of interest (ROIs), one in the lung (usually the left one) and another one over the myocardium of the left ventricle, delineated in the anterior images (Gill et al., 1987; Hurwitz et al., 1992; Kurata et al., 1991; 
Mahmood et al., 1992). However, there is a general discrepancy in the reported LHR normal values, depended mainly on the method of calculation. For Tl-201, LHR upper normal limits range in the literature from approximately 0.37 to 0.55 (Georgoulias et al., 2010a). Increased exercise Tl-201 uptake is associated with decreased left ventricular function, the presence of multiple-vessel CAD, and poor patient prognosis (Brown, 1997; Chin et al., 1996; Daou et al., 2000; Gill et al., 1987; Kurata et al., 1991; Morel et al., 1999). Kurata et al. have found that patients with abnormal Tl-201 lung uptake had more extensive multiple-vessel CAD, more severe left ventricular dysfunction, and more perfusion defects than did patients with normal Tl201 pulmonary activity (Kurata et al., 1991).

Follow-up studies have shown that abnormal lung Tl-201 uptake is in general a significant predictor of subsequent adverse cardiac events for patients undergoing an MPI. Moreover, the Tl-201 LHR prognostic value has been reported in specific subgroups such as in patients treated with thrombolytic therapy during acute myocardial infarction, in patients with unstable angina and non-Q myocardial infarction, in patients after coronary artery bypass grafting, in patients with left ventricular apical aneurysm and in patients with severe postischaemic left ventricular dysfunction or after heart transplantation (Dakik et al., 1996; Jain et al., 1997; Krawczynska et al., 1997; Marcassa et al., 2000; Sarda et al., 2001; Wu et al., 2005). Abnormal pulmonary Tl-201 uptake during stress (treadmill or pharmacologic test) imaging has similar clinical significance to that noted during exercise. Thus, high uptake of Tl-201 in the lungs has an important prognostic value (Brown, 1997; Chin et al., 1996; Daou et al., 2000; Gill et al., 1987; Morel et al., 1999). Moreover, published data present an incremental prognostic value of increased Tl-201 pulmonary uptake over clinical, stress testing and other imaging findings, providing clinically useful risk assessment (Marcassa et al., 2000).

\subsection{Tc-99m sestamibi pulmonary uptake}

Although technetium-based radiopharmaceuticals have been widely used for several years, their limited use in lung uptake assessment has been regarded as a potential drawback. The results of assessing Tc-99m sestamibi pulmonary-to heart ratio of activity on conventional images obtained 30-60 min after stress are ambiguous, while a few studies have suggested that measuring lung uptake of Tc-99m sestamibi on immediate post-stress images may be more valuable (Bacher-Stier et al., 2000; Choy \& Leslie, 2001; Giubbini et al., 1995; Hurwitz et al., 1993; Hurwitz et al., 1996; Hurwitz et al., 1998; Hurwitz, 2000; Patel et al., 2004; Romanens et al., 2001; Saha et al., 1994). In addition, the methodology for calculating LHR among investigators varies; for example, a large ROI that enclosed the entire left ventricle or most of the left ventricle respectively and a fixed-size ROI in the left lung (Choy \& Leslie, 2001; Patel et al., 2004). Other widely used methods are the following: a transmural segment of the myocardium is outlined containing the area of peak counts and a crescenting ROI placed over the left lung or alternatively, a fixed small rectangular ROI placed over maximal myocardial and left lung activity (Hurwitz et al., 1993; Hurwitz et al., 1996; Hurwitz et al., 1998; Hurwitz, 2000; Romanens et al., 2001). Thus, the reported LHR normal values for Tc$99 \mathrm{~m}$ sestamibi vary significantly between 0.44 and 0.56 , depended on the method of calculation and the time interval between radiotracer's injection and the acquisition of the image for the LHR calculation, although early post-stress calculated values are generally higher than those calculated during the standard acquisition time (Georgoulias et al., 2010a). In addition, conflicting results have been reported about the relation between the values of LHR measured in the delayed images and the presence of extensive myocardial ischaemia 
or severe CAD (Bacher-Stier et al., 2000; Choy \& Leslie, 2001; Patel et al., 2004; Saha et al., 1994). On the other hand, the clinical value of Tc-99m sestamibi LHR obtained almost immediately after stress (exercise or vasodilatation), has been reported in several studies (Flamen et al., 1995; Münch et al., 1997; Nakajima et al., 1993). They have found that increased pulmonary to myocardial ratio calculated on early post-stress images was associated with severe scintigraphic abnormalities and angiographic findings (mainly threevessel disease or stenoses in the left mainstem), in concordance to Tl-201 post-stress lung uptake (Hurwitz et al., 1993; Hurwitz et al., 1998; Hurwitz, 2000; Romanens et al., 2001). In addition, Leslie et al. have reported the prognostic value of lung sestamibi uptake in a cohort of 718 patients with known or suspected CAD, who underwent a Tc-99m sestamibi MPI (Leslie et al., 2005).

\subsection{Tc-99m tetrofosmin pulmonary uptake}

As we have already mentioned Tc- $99 \mathrm{~m}$ tetrofosmin is an interesting alternative radiopharmaceutical for MPS, as it combines the exceptional physical properties of Tc-99m with easy and fast preparation (Georgoulias et al., 1996; Heo et al., 1994; Nakajima et al., 1993; Sridhara et al., 1993). The diagnostic and prognostic value of myocardial perfusion SPECT studies using this radiotracer has already been well established, although a few studies have utilized the usefulness of lung uptake as an ancillary parameter.

We have mentioned above the significant variability of the applied techniques for calculating LHR using Tc-99m labeled tracers. For the quantification of Tc-99m tetrofosmin pulmonary uptake, in our Nuclear Medicine Laboratory we acquire early anterior planar images (1000 kcounts, matrix 256X256), 4-6 min after radiotracer injection at stress (early post-stress images), considering that Tc-99m tetrofosmin has a rapid clearance from the lungs. We then delineate two ROIs: one square, 15X15 pixels, placed over the left mid-lung area at the vicinity of the myocardium (at a distance of at least 3 pixels above the anterolateral wall - 'lung ROI') and the other, manually drown irregular ROI, including the whole myocardial activity of the left ventricle ('myocardial ROI') (Choy \& Leslie, 2001; Georgoulias et al., 2006; Patel et al., 2004) (Fig. 1). The pulmonary/heart ratio was determined as the mean counts/pixel in the lung ROI divided by the mean counts/pixel in the myocardial ROI (Choy \& Leslie, 2001; Giubbini et al., 1995; Homma et al., 1987; Hurwitz et al., 1992; Hurwitz et al., 1998; Kaul et al., 1998; Kurata et al., 1991; Liu et al., 1985; Patel et al., 2004; Tanigaki et al., 1998; Tsou et al., 2002). Our method for calculating Tc-99m tetrofosmin LHR is similar to that used by Choy \& Leslie (Choy \& Leslie, 2001) and Patel et al. (Patel et al., 2004). This approach may underestimate the counts from the heart, if severe defects are present, thus potentially overestimating the LHR value. On the other hand, this method avoids problems related to hot spots or other artefacts that could have erroneous effects on LHR. We believe that our method is more representative of pulmonary and heart radioactivity, especially in cases with regional myocardial ischemia.

The mechanism of lung uptake with Tc-99m labeled myocardial perfusion tracers has not been directly established, but it is reasonable to consider that it shares similarities with Tl201 lung uptake. Our findings (presenting below) that CAD severity, scintigraphic ischaemic abnormalities and clinical-exercise data of myocardial ischaemia have a considerable correlation with stress LHR, support the role of ischaemic left ventricular dysfunction with subsequent pulmonary congestion-increased pulmonary vascular transit time as previously suggested for thallium (although additional factors may be also important) (Choy \& Leslie, 2001; Georgoulias et al., 2006). 

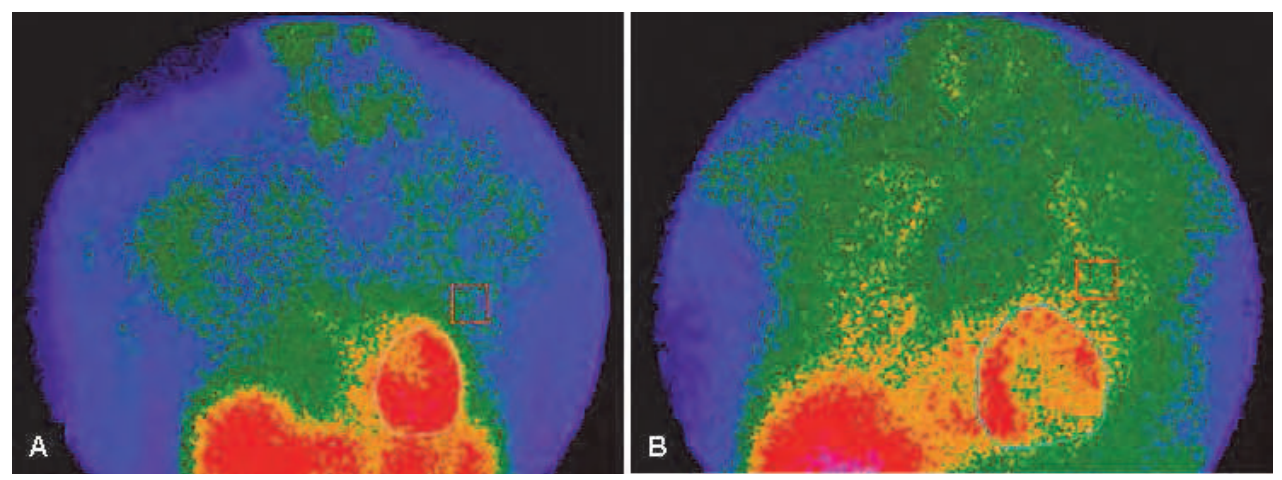

RCA: right coronary artery; LCX: left circumflex artery; LAD: left anterior descending artery

Fig. 1. (A) Normal early post-stress LHR value (0.402) in a 50-year-old woman without CAD. (B) Elevated early post-stress LHR value (0.693) in a 61-year-old man with 3-vessel disease (RCA 95\%, LCX 95\%, LAD 80\%) (Reprinted from European Journal of Nuclear Medicine and Molecular Imaging, Vol. 37, Georgoulias, P., Tsougos, I., Valotassiou, V., Tzavara, C., Xaplanteris, P., \& Demakopoulos, N., Long-term prognostic value of early poststress $(99 \mathrm{~m})$ Tc-tetrofosmin lung uptake during exercise (SPECT) myocardial perfusion imaging, pp. 789-798, Fig. 1, 2010, with kind permission from Springer Science \& Business Media B.V.).

In 2006, we published our results of studying 158 consecutive patients who underwent a stress/rest Tc-99m tetrofosmin myocardial SPECT (rest scans were obtained as gated SPECT) and coronary angiography (Georgoulias et al., 2006). An early post-stress LHR value of 0.500 was defined as the upper normal limit, taking into consideration the early post-stress LHR values calculated in a normal group and using the formula 'mean value \pm $2 \mathrm{SD}^{\prime}$. Patients with a normal early post-stress LHR value generally had a better performance in the treadmill testing than those with an abnormal value, had significantly better myocardial perfusion and function and better angiographic results (Georgoulias et al., 2006). We found a significant correlation $(\mathrm{P}<0.001)$ among early post stress LHR, summed stress score (SSS) and the number of stenosed vessels (Georgoulias et al., 2006). The associations between the values of early post-stress LHR and summed difference score (SDS), left ventricular ejection fraction $(\mathrm{LVEF})$ were weaker $(\mathrm{P}=0.031, \mathrm{P}=0.017)$. The incidence of multivessel CAD in the subgroup of patients with increased values of early post-stress LHR, was significantly higher than in the normal group ( $81 \%$ vs. $42 \%, \mathrm{P}<0.001)$ (Georgoulias et al., 2006). We also reported a significant difference $(P<0.001)$ of the early post stress LHR value between patients with normal coronary arteries or one-vessel disease and patients with multi-vessel disease (Fig. 2). The above-mentioned data could be attributed to the influence of ischaemia on the early post-stress LHR value and are generally analogous with other published data, while other investigators did not find similar results using Tc-99m sestamibi as the radiotracer (Hurwitz et al., 1993; Hurwitz et al., 1998; Saha et al., 1994).

Moreover, early post-stress LHR was an independent predictor of multi-vessel CAD (coefficient 1.85, SD 0.16, $\mathrm{P}<0.001$ ), with an incremental value for its identification (Georgoulias et al., 2006). Similar results have been presented by Tsou et al., Tanigaki et al. and Okajima et al. who have also reported the incremental value of Tc- $99 \mathrm{~m}$ tetrofosmin 


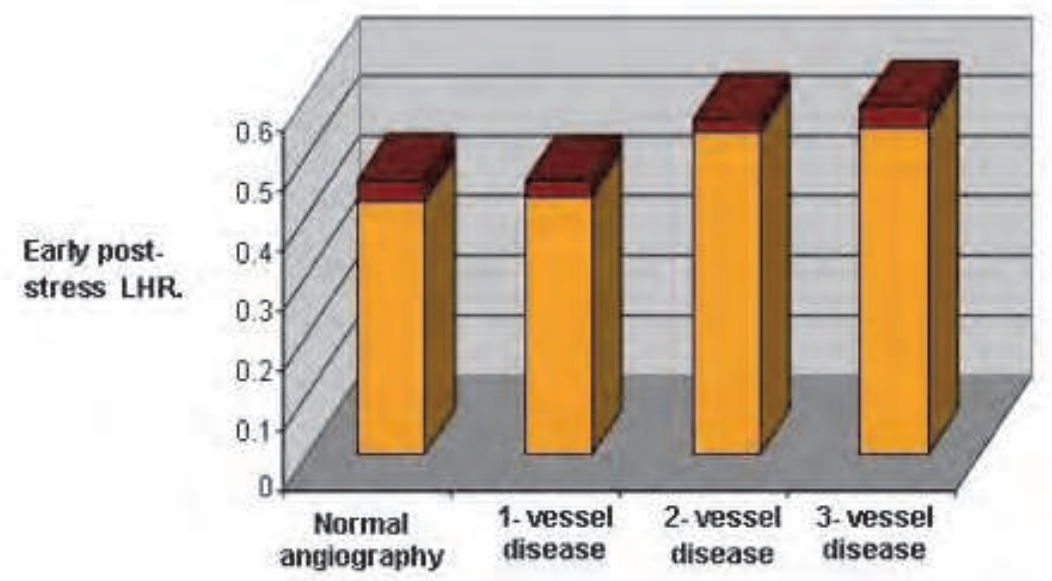

Fig. 2. Mean value $( \pm S D)$ of early post-stress LHR, in patients with normal angiography, onevessel disease, two-vessel disease and three-vessel disease (Reprinted from Nuclear Medicine Communications, Vol. 27, Georgoulias, P., Demakopoulos, N., Kontos, A., Xaplanteris, P., Xydis, K., \& Fezoylidis, I., Early post-stress pulmonary uptake of 99m Tc tetrofosmin during exercise (SPECT) myocardial perfusion imaging: correlation with haemodynamic, perfusion and function parameters, pp. 119-126, 2006, with kind permission from Wolters Kluwer Health).

LHR, compared to conventional MPI, for the detection of multi-vessel disease (Okajima et al., 2004a; Tanigaki et al., 1998; Tsou et al., 2002). Specifically, the early post-stress LHR added incremental value to clinical, exercise testing, and myocardial perfusion and function data, for the identification of patients with multi-vessel CAD. In detail, if the cut-off point of early post-stress LHR value was set at 0.500 , the sensitivity, positive and negative predictive value to detect multi-vessel CAD improved from $87 \%, 84 \%$ and $82 \%$ to $94 \%, 85 \%$ and $91 \%$, respectively, while the specificity did not change considerably (78\%) (Georgoulias et al., 2006).

On the other hand there are only few published data about the Tc-99m tetrofosmin LHR prognostic value (Casáns Tormo et al., 2001). In a previously published manuscript, we have evaluated the long-term prognostic value of early post-stress Tc-99m tetrofosmin LHR, in a cohort of 276 patients who were investigated with stress/rest Tc-99m tetrofosmin myocardial gated-SPECT (rest studies) and coronary angiography. During a mean follow-up period of 32.4 months $(\mathrm{SD}=9.6)$ hard cardiac events (cardiovascular death and non-fatal myocardial infarction) occurred in $28(10.1 \%)$ patients and soft cardiac events (revascularization procedures) in 32 (11.6\%) patients (Georgoulias et al., 2010a). Implying multiple Cox regression analysis with stepwise-forward approach, early post-stress LHR was found to be a significant independent predictor for both soft and hard cardiac events. The hazard ratio (for 0.1 unit increase) was 4.41 (95\%CI: $1.52-12.73, \mathrm{p}=0.006$ ) for soft cardiac events and 4.22 (95\%CI: 2.07 - 8.62, p<0.001) for hard cardiac events. The other significant prognostic factors were use of $\beta$-blockers, SSS and use of nitrates for soft events and exercise duration and SSS for hard cardiac events (Georgoulias et al., 2010a). 
The cumulative soft event-free rates for one, two and five years were $100 \%(\mathrm{SE}=0 \%), 99.2 \%$ $(\mathrm{SE}=0.8 \%)$ and $92.8 \%(\mathrm{SE}=3.2 \%)$ for patients with early post-stress LHR value less than 0.500 and $98.5 \%(\mathrm{SE}=1.0 \%), 96.1 \%(\mathrm{SE}=1.7 \%)$ and $63.5 \%(\mathrm{SE}=5.8 \%)$ for patients with early poststress LHR value more than 0.500 , respectively. Finally, the cumulative hard event-free rates for one, two and five years were $100 \%(\mathrm{SE}=0 \%), 99.2 \%(\mathrm{SE}=0.8 \%)$ and $89.8 \%(\mathrm{SE}=3.7 \%)$ for patients with early post-stress LHR value less than 0.500 and $98.5 \%$ (SE=1.1\%), 92.1\% $(\mathrm{SE}=2.4 \%)$ and $75 \%(\mathrm{SE}=5.0 \%)$ for patients with early post-stress LHR value more than 0.500 , respectively (Fig. 3, 4).

Furthermore, the incremental prognostic value of early post-stress LHR was evaluated by a statistically significant increase in the global chi-square of the Cox proportional-hazard model that included clinical, exercise, angiographic and scintigraphic variables (Valotassiou et al., 2009). Using ROC analysis, the optimal sensitivity and specificity of various early post-stress LHR cut-off values for the prediction of cardiac events, was determined. ROC curve analysis showed that the optimal cut-off of early post-stress LHR for the prediction of soft cardiac events was 0.527 with sensitivity equal to $78.1 \%$ and specificity equal to 80.7 (Valotassiou et al., 2009). Similarly, the early post-stress LHR value of 0.530 represented the optimal cut-off for the prediction of hard cardiac events (sensitivity 68\% and specificity

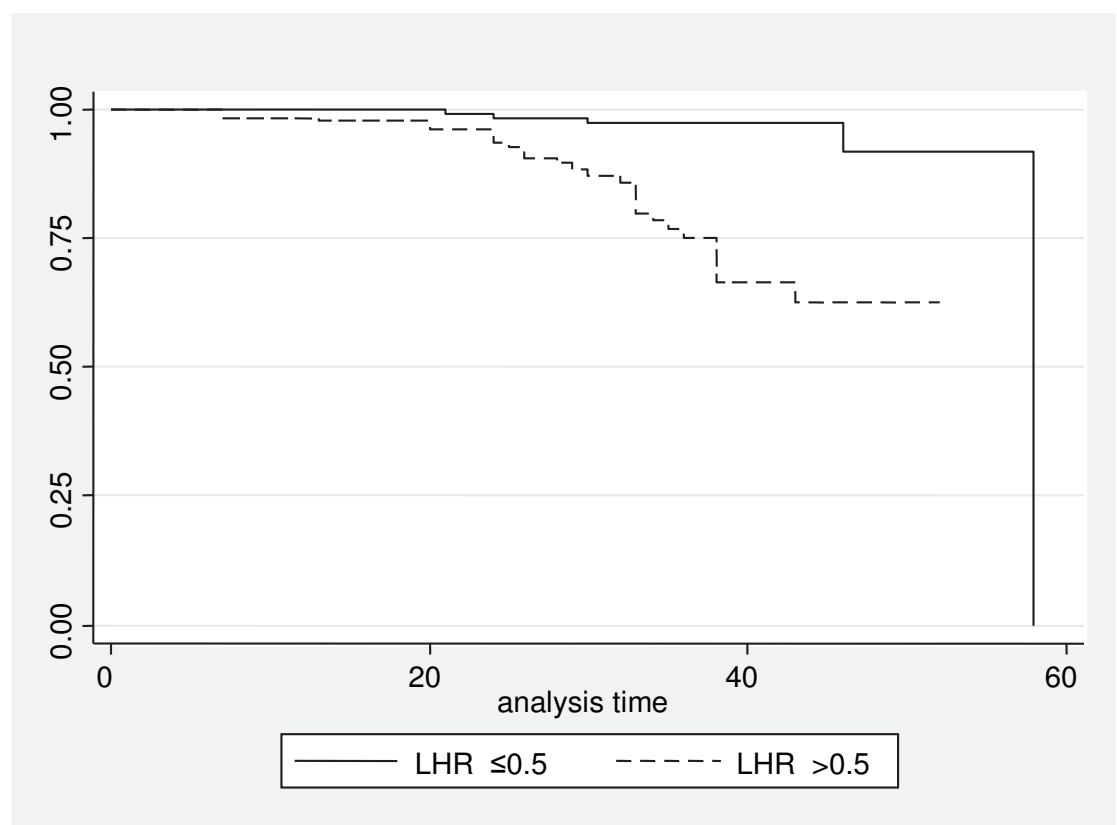

Fig. 3. Kaplan-Meier estimates for soft cardiac events according to early post-stress LHR levels (Reprinted from European Journal of Nuclear Medicine and Molecular Imaging, Vol. 37, Georgoulias, P., Tsougos, I., Valotassiou, V., Tzavara, C., Xaplanteris, P., \& Demakopoulos, N., Long-term prognostic value of early poststress $(99 \mathrm{~m})$ Tc-tetrofosmin lung uptake during exercise (SPECT) myocardial perfusion imaging, pp. 789-798, Fig. 2, 2010, with kind permission from Springer Science \& Business Media B.V.). 
78.6\%). The area under the curve (AUC) was 0.80 (95\% CI: 0.71 - 0.88) and 0.76 (95\% CI: 0.66$0.86)$, for soft and hard cardiac events, respectively. The addition of early post-stress LHR in the Cox regression model, included clinical, exercise data and myocardial perfusion SSS, increased significantly the global chi-square for both soft and hard cardiac events $(p<0.001)$ declaring the significant incremental value of early post-stress LHR. The adjusted hazard ratios for early post-stress LHR more than 0.53 were 9.44 and 7.51 (95\% CI: 3.13 - 28.41, $\mathrm{P}<0.001$ ) for soft and hard cardiac events, respectively (Valotassiou et al., 2009).

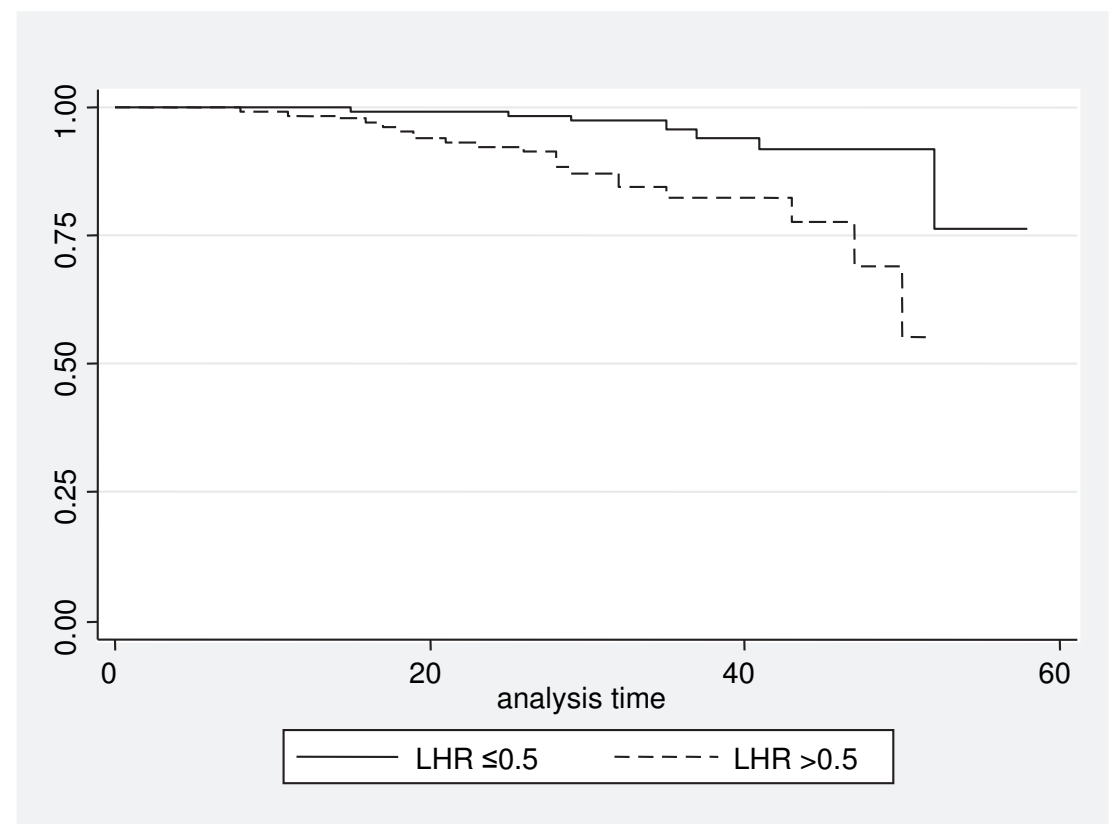

Fig. 4. Kaplan-Meier estimates for hard cardiac events according to early post-stress LHR levels (Reprinted from European Journal of Nuclear Medicine and Molecular Imaging, Vol. 37, Georgoulias, P., Tsougos, I., Valotassiou, V., Tzavara, C., Xaplanteris, P., \& Demakopoulos, N., Long-term prognostic value of early poststress $(99 \mathrm{~m})$ Tc-tetrofosmin lung uptake during exercise (SPECT) myocardial perfusion imaging, pp. 789-798, Fig.3, 2010, with kind permission from Springer Science \& Business Media B.V.).

To summarize, early post-stress Tc-99m tetrofosmin LHR appeared to be a useful index of extensive myocardial ischaemia, heart dysfunction and multi-vessel CAD (Georgoulias et al., 2006). Moreover, our results suggest that early post-stress LHR is an independent and powerful predictor for both hard (death or myocardial infarction) and soft cardiac events (revascularization procedures), providing incremental prognostic information to that provided by clinical, exercise testing and scintigraphic data (Georgoulias et al., 2010a; Valotassiou et al., 2009). In addition, an early post-stress LHR value of 0.53 was the optimalcut off for the prediction of any cardiac event and could be useful in clinical practice, contributing to more accurate patient risk stratification with valuable influence on their therapy (Valotassiou et al., 2009). 


\section{Incidental pathologic extra-cardiac findings during MPI}

Extra-cardiac findings during acquisition of MPS (using Tl-201 or Tc-99m labeled radiotracers) can be visualized in the area being viewed, including mainly the thorax and the upper abdomen, depending on the patient body size and the camera field of view (Kim et al., 2002; Vijayakumar et al., 2005). These extra-cardiac uptake accumulations may be benign or malignant and require further investigation which might be life saving for the patient (Kim et al., 2002; Vijayakumar et al., 2005). After intravenous administration, normal uptake of Tc-99m tetrofosmin is seen in several organs, most commonly localized in the heart, lungs, breasts mainly during lactation and lymph nodes, while in the abdomen significant normal uptake can occur in the liver, gall bladder and bowel (Vijayakumar et al., 2005). Elimination of the radiotracer occurs mostly through the kidneys and the hepatobiliary system (Hesse et al., 2005).

Pathologic uptake of Tc-99m tetrofosmin can occur in benign or malignant tumors and also in infectious or non-infectious diseases (Vijayakumar et al., 2005). The mechanism of uptake of Tc-99m tetrofosmin in non-cardiac lesions is not completely understood, but the size of the lesion, its mitochondrial-rich cellularity and perfusion (factors) play a significant role (Kinuya et al., 2003; Sükan et al., 2004). Over-expression of P-glycoprotein or multi-drug resistance can decrease tumor uptake and are also associated with resistance to cancer treatment. Benign Tc-99m tetrofosmin incidental extra-cardiac uptake in the neck and chest has been reported in thyroid diseases, parathyroid adenomas, benign lymph node hyperplasia, esophagitis, neurofibroma, smoker's lung, lung infections, sarcoidosis and scapular hibernoma (Bestetti et al., 1996; Kannan et al., 2007; Oller et al., 2001; Vijayakumar et al., 2005). Photopenia in the lung bases due to pleural effusions and abnormal right liver configuration caused by elevation of the right hemi-diaphragm has also been reported during Tc-99m tetrofosmin MPS (Shih et al., 2002). In neck and chest malignant diseases, extra-cardiac uptake has been reported in: thyroid cancer, neuroendocrine tumors, mediastinal tumors, lung cancer, breast cancer, esophageal carcinoma, lymphoma, Kaposi's sarcoma, multiple myeloma and in nasopharyngeal cancer (Khairallah et al., 2002; Okajima et al., 2004b; Torreggiani et al., 1999; Vijayakumar et al., 2005). Moreover, Tc-99m tetrofosmin incidental uptake in abdominal abnormalities has been detected during cardiac acquisition, when the area being viewed includes the lower thorax and the upper abdomen, in abnormalities of the liver, gallbladder, kidneys, oesophagus, stomach, bowel and bone marrow (Shih et al., 2002). Hepatocellular carcinoma, melanoma, sarcomas and multiple myeloma have also been described in the abdomen, accumulating Tc-99m tetrofosmin in MPS (Fisher et al., 2000; Hadase et al., 2003; Vijayakumar et al., 2005; Yi \& Jacobs, 2004).

Others, reviewing the raw data cine images of 566 patients during Tl-201 dipyridamole Tc99m tetrofosmin rest-stress MPS, found 234 abnormalities (Shih et al., 2002; Shih et al., 2005) such as: bone marrow visualisation $(39.7 \%)$, duodenogastric and enterogastric reflux $(20.1 \%)$, non-visualisation of the gallbladder (13.2\%), small-atrophic-scarred, vaguely seen or ectopic kidneys, splenomegaly, liver diseases like hepatomegaly and cirrhosis and breast attenuation causing photopenia in the liver. The authors suggested that Tc-99m tetrofosmin is accumulated in the red bone marrow due to high and/or expanded haematopoetic activity. It is obvious that all these coincidental abdominal abnormalities should alert the referring physician to suggest further investigation. In addition, duodenogastric and enterogastric refluxes, which represent approximately $20 \%$ of the abdominal abnormalities, may cause symptoms mimicking angina. Recently, Gratz et al. reported six patients with 
unexpected abnormal mediastinal and/or thoracic activities, out of 2155 who underwent Tc-99m tetrofosmin MPI. Subsequently, the patients underwent resection of a thymoma $(n=2)$, nonsmall cell lung cancer $(n=1)$ and breast cancer $(n=3)$ (Gratz et al., 2008).

We have previously published an unusual case of a 60 year-old woman with atypical precardiac symptoms who underwent Tc-99m tetrofosmin stress - rest SPECT imaging (Kotsalou et al., 2008). The MPI gated-study was normal. However, an incidental finding of intense extra-cardiac uptake of the radiotracer in the left paracardiac area was observed (Fig. 5).
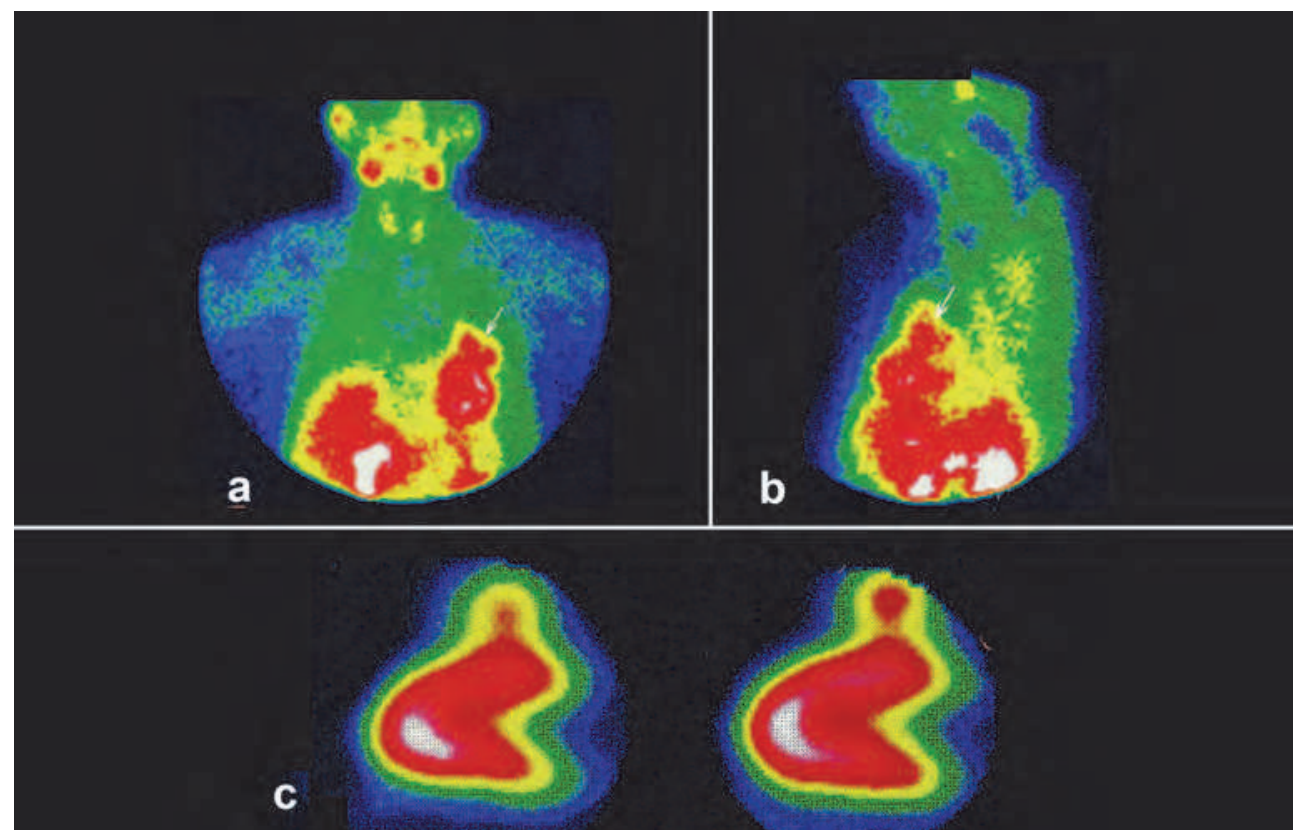

STRESS

REST

Fig. 5. Anterior (a) and left lateral (b) projections of the thorax, demonstrated intense Tc-99m tetrofosmin uptake in the left paracardiac area (arrows). Myocardial perfusion SPET imaging was normal (c) (Reprinted from Hellenic Journal of Nuclear Medicine, Vol. 11, Kotsalou, I., Georgoulias, P., Fourlis, S., Zoumboulidis, A., Giaslakiotis, K., Androulaki, A., Chronopoulos, P., \& Dimakopoulos, N., Incidental pathologic extracardiac uptake of 99mTc-tetrofosmin in myocardial perfusion imaging, pp. 43-45, 2008, with kind permission from the Hellenic Society of Nuclear Medicine).

The computerized tomography (CT) and magnetic resonance imaging (MRI) tests revealed a mass of $6 \mathrm{~cm}$ diameter in the left lower anterior mediastinal area (Fig. 6). The patient after a biopsy underwent surgical resection of the mass through medial sternotomy followed by adjuvant radiotherapy of the mediastinum, because of microscopic invasion of the capsule. The histologic-immunochistochemical examination established the diagnosis of a thymoma type $\mathrm{AB}$ and stage $2 \mathrm{~b}$ (Masaoka II2 and TNM Pt2) (Fig. 7). 


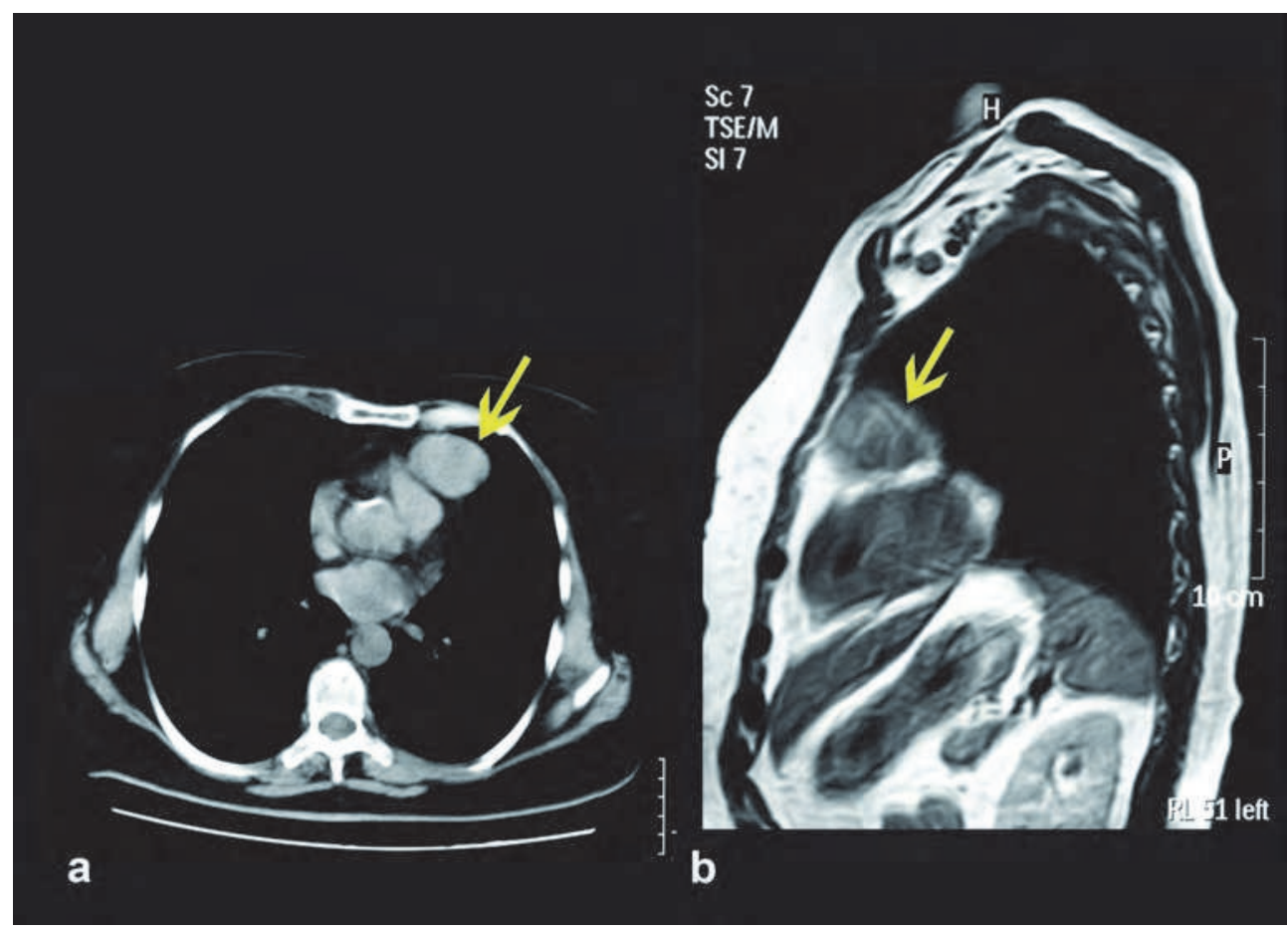

Fig. 6. Computed tomography (a) and magnetic resonance imaging (b) revealed a solid mass located in the left lower anterior mediastinal area, in contact but not infiltrating pericardium, while signs of pressing the left lung were also noticed (arrows). Thymoma was the possible diagnosis (Reprinted from Hellenic Journal of Nuclear Medicine, Vol. 11, Kotsalou, I., Georgoulias, P., Fourlis, S., Zoumboulidis, A., Giaslakiotis, K., Androulaki, A., Chronopoulos, P., \& Dimakopoulos, N., Incidental pathologic extracardiac uptake of 99mTc-tetrofosmin in myocardial perfusion imaging, pp. 43-45, 2008, with kind permission from the Hellenic Society of Nuclear Medicine).

Other authors have also reported cases of incidental thymoma detection during MPS (Chadika et al., 2005; Douglas et al., 2000; Rebollo Aguirre et al., 2003; Sciagrà et al., 1998; Vijayakumar et al., 2004; Vijayakumar et al., 2005). Moreover, Douglas et al. reviewed three cases of incidental occult thymoma, detected during dual isotope Tl-201 and Tc-99m tetrofosmin SPECT imaging (Douglas et al., 2000). The authors suggested that solitary extracardiac uptake on Tc-99m images without Tl-201 uptake, corresponds to well- differentiated tumors, while the opposite corresponds to poorly-differentiated thymoma (Douglas et al., 2000).

\section{Conclusion}

In conclusion, early post-stress Tc-99m tetrofosmin LHR has a significant clinical value, as a useful index of extensive myocardial ischaemia, heart dysfunction and multi-vessel CAD. Moreover, early post-stress LHR appears as an independent and powerful predictor, 


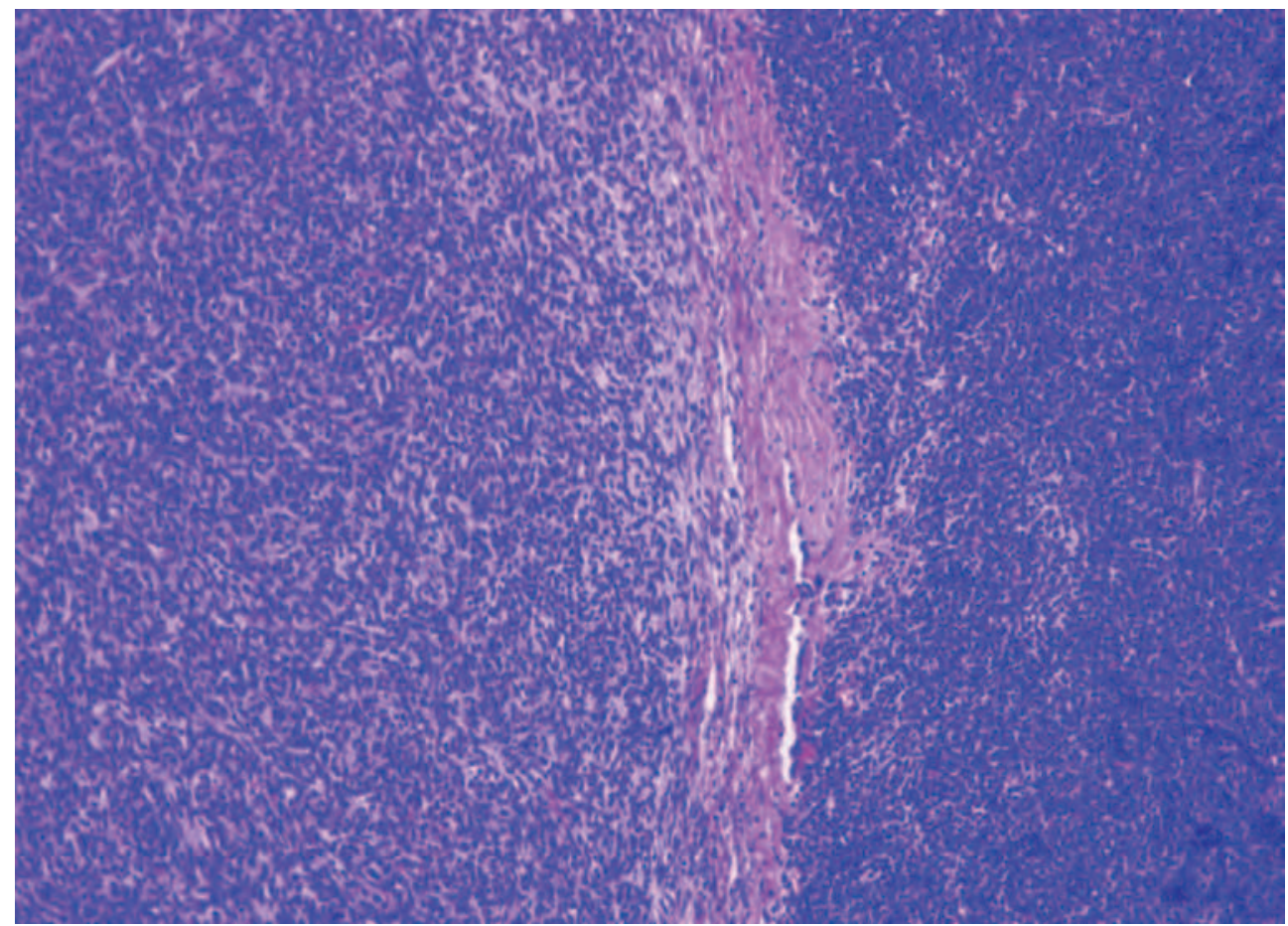

Fig. 7. Histologic and immunochistochemical examination confirmed the diagnosis of a mixed type AB thymoma, stage Masaoka II2 and TNM Pt2 (Reprinted from Hellenic Journal of Nuclear Medicine, Vol. 11, Kotsalou, I., Georgoulias, P., Fourlis, S., Zoumboulidis, A., Giaslakiotis, K., Androulaki, A., Chronopoulos, P., \& Dimakopoulos, N., Incidental pathologic extracardiac uptake of $99 \mathrm{mTc}$-tetrofosmin in myocardial perfusion imaging, pp. 43-45, 2008, with kind permission from the Hellenic Society of Nuclear Medicine).

assigning incremental prognostic information to that provided by clinical, exercise testing and scintigraphic data. In addition, an LHR value of 0.53 was the optimal-cut off for the prediction of any cardiac event and could be useful in clinical practice. It seems that the clinical value of routine pulmonary uptake measurements during Tc-99m tetrofosmin myocardial scintigram, in immediate post-stress images, as an ancillary scintigraphic sign, will maximize not only the information it provides for the assessment of the severity of myocardial ischaemia and CAD, but also the prognostic value of the study. In an era where a continuous effort is underway for deriving as many elements as possible from the examinations, the calculation of early post-stress LHR during myocardial perfusion imaging may contribute to a better (more accurate) patient risk stratification with valuable influence on their therapy.

Additionally, careful inspection of projection images should be an integral part of interpreting MPI studies. According to the literature, during Tc-99m tetrofosmin MPI various incidental extra-cardiac neck, chest and abdominal abnormalities have been detected. Even though MPI is performed for cardiac evaluation, Nuclear Medicine physicians should be aware of non-cardiac uptake of the radiotracer which can play an 
essential role in early tumor detection resulting in life-saving early therapy. Any extracardiac focal uptake of Tc-99m tetrofosmin requires attention of the interpreting physician and has to be mentioned in the report, guiding the referring physician to request further investigation. The identification of these coincidental findings is significant for the early detection of the coexisting pathology and may prove to be essential in saving patient's life.

\section{Acknowledgment}

The authors thank Sotiria Gerasimou-Angelidi, MSc for her contribution.

\section{References}

Anagnostopoulos, C., Harbinson, M., Kelion, A., Kundley, K., Loong, C.Y., Notghi, A., Reyes, E., Tindale, W., \& Underwood, S.R. (2003). Procedure guidelines for radionuclide myocardial perfusion imaging. Nuclear Medicine Communications, Vol. 24, No. 10, (October 2003), pp. 1105-1119, ISSN 0143-3636

Bacher-Stier, C., Sharir, T., Kavanagh, P.B., Lewin, H.C., Friedman, J.D., Miranda, R., Germano, G., \& Berman, D.S. (2000). Postexercise lung uptake of 99mTc-sestamibi determined by a new automatic technique: validation and application in detection of severe and extensive coronary artery disease and reduced left ventricular function. Journal of Nuclear Medicine, Vol. 41, No. 7, (July 2000), pp. 1190-1197, ISSN 0161-5505

Bateman, T.M., O'Keefe, J.H. Jr, Dong, V.M., Barnhart, C., \& Ligon, R.W. (1995). Coronary angiographic rates after stress single-photon emission computed tomographic scintigraphy. Journal of Nuclear Cardiology, Vol. 2, No. 3, (May - June 1995), pp. 217 223, ISSN 1071-3581

Bestetti, A., Posterli, R., Chiapparino, R., Pedrazzini, L., \& Tarolo, G.L. (1996). Tc-99m tetrofosmin lymph node uptake in myocardial perfusion imaging. Clinical Nuclear Medicine, Vol. 21, No. 6, (June 1996), pp. 486-487, ISSN 0363-9762

Brown, K.A. (1991). Prognostic value of thallium-201 myocardial perfusion imaging. A diagnostic tool comes of age. Circulation, Vol. 83, No. 2, (February 1991), pp. 363381, ISSN 0009-7322

Brown, K.A. (1995). Prognostic value of cardiac imaging in patients with known or suspected coronary artery disease: comparison of myocardial perfusion imaging, stress echocardiography, and positron emission tomography. The American Journal of Cardiology, Vol. 75, No. 11, (April 1995), pp. D35-D41, ISSN 0002-9149

Brown, K.A. (1996). Prognostic value of myocardial perfusion imaging: state of the art and new developments. Journal of Nuclear Cardiology, Vol. 3, No. $6 \mathrm{Pt}$ 1, (November December 1996), pp. 516-537, ISSN 1071-3581

Brown, K.A. (1997). Prognostic value of nuclear cardiology techniques, In: Cardiac Nuclear Medicine, M.C. Gerson, (Ed.), pp. 619-654, McGrawHill, ISBN 0-07-032848-X, New York, USA

Casáns Tormo, I., Llácer Escorhihuela, A., Ferrero Cabedo, J.A., Otero Coto, E., Ciudad Platero, J., \& Manjón Soriano, J. (2001). Prognostic value of myocardial perfusion SPECT in multivessel coronary disease patients with left ventricular dysfunction, 
comparing revascularized and non-revascularized patients. Revista Española de Medicina Nuclear, Vol. 20, No. 6, (October 2001), pp. 443-452, ISSN 0212-6982

Chadika, S., Kokkirala, A.R., Giedd, K.N., Johnson, L.L., Giardina, E.G., \& Bokhari, S. (2005). Focal uptake of radioactive tracer in the mediastinum during SPECT myocardial perfusion imaging. Journal of Nuclear Cardiology, Vol. 12, No. 3, (May - June 2005), pp. 359-361, ISSN 1071-3581

Chin, B.B., Moshin, J., Bouchard, M., Berlin, J.A., Araujo, L.I., \& Alavi, A. (1996). Hemodynamic indices of myocardial dysfunction correlate with dipyridamole thallium-201 SPECT. Journal of Nuclear Medicine, Vol. 37, No. 5, (May 1996), pp. 723729, ISSN 0161-5505

Choy, J.B. \& Leslie, W.D. (2001). Clinical correlates of Tc-99m sestamibi lung uptake. Journal of Nuclear Cardiology, Vol. 8, No. 6, (November 2001), pp. 639-644, ISSN 1071-3581

Dakik, H.A., Mahmarian, J.J., Kimball, K.T., Koutelou, M.G., Medrano, R., \& Verani, M.S. (1996). Prognostic value of exercise 201Tl tomography in patients treated with thrombolytic therapy during acute myocardial infarction. Circulation, Vol. 94, No. 11, (December 1996), pp. 2735-2742, ISSN 0009-7322

Daou, D., Delahaye, N., Lebtahi, R., Vilain, D., Peker, C., Faraggi, M., \& Le Guludec, D. (2000). Diagnosis of extensive coronary artery disease: intrinisic value of increased lung 201 T1 uptake with exercise SPECT. Journal of Nuclear Medicine, Vol. 41, No. 4, (April 2000), pp. 567-574, ISSN 0161-5505

Douglas, E., Paull, D.E., Graham, J., Forgetta, J., Turissini, T., \& Saidman, B. (2000). Detection of occult thymoma during exercise thallium 201, technetium $99 \mathrm{~m}$ tetrofosmin imaging for coronary artery disease. Chest, Vol. 118, No. 2, (August 2000), pp. 550551, ISSN 0012-3692

Fisher, C., Vehec, A., Kashlan, B., Longa, G., Houpt, L., Howe, K., Stark, L., \& Cavanaugh, D. (2000). Incidental detection of skeletal uptake on sestamibi cardiac images in a patient with previously undiagnosed multiple myeloma. Clinical Nuclear Medicine, Vol. 25, No. 3, (March 2000), pp. 213-214, ISSN 0363-9762

Flamen, P., Bossuyt, A., \& Franken, P.R. (1995). Technetium-99m-tetrofosmin in dipyridamole-stress myocardial SPECT imaging: intraindividual comparison with technetium-99m-sestamibi. Journal of Nuclear Medicine, Vol. 36, No. 11, (November 1995), pp. 2009-2015, ISSN 0161-5505

Geleijnse, M.L., Elhendy, A., van Domburg, R.T., Cornel, J.H., Reijs, A.E., \& Fioretti, P.M. (1996). Prognostic significance of normal dobutamine-atropine stress sestamibi scintigraphy in women with chest pain. The American Journal of Cardiology, Vol. 77, No. 12, (May 1996), pp. 1057-1061, ISSN 0002-9149

Georgoulias, P., Demakopoulos, N., Kontos, A., Xaplanteris, P., Thomadakis, K., Mortzos, G., \& Karkavitsas, N. (1996). Myocardial perfusion scintigraphy using 99mTCtetrofosmin: a comparison with coronary angiography. Nuklearmedizin, Vol. 35, No. 5, (October 1996), pp. 153-155, ISSN 0029-5566

Georgoulias, P., Demakopoulos, N., Kontos, A., Xaplanteris, P., Thomadakis, K., Mortzos, G., \& Karkavitsas, N. (1998). Tc-99m tetrofosmin myocardial perfusion imaging before and six months after percutaneous transluminal coronary angioplasty. 
Clinical Nuclear Medicine, Vol. 23, No. 10, (October 1998), pp. 678-682, ISSN 03639762

Georgoulias, P., Demakopoulos, N., Kontos, A., Xaplanteris, P., Xydis, K., \& Fezoylidis, I. (2006). Early post-stress pulmonary uptake of $99 \mathrm{~m}$ Tc tetrofosmin during exercise (SPECT) myocardial perfusion imaging: correlation with haemodynamic, perfusion and function parameters. Nuclear Medicine Communications, Vol.27, No. 2, (February 2006), pp. 119-126, ISSN 0143-3636

Georgoulias, P., Valotassiou, V., Wozniak, G., Demakopoulos, N., \& Fezoulidis, I. (2008). Myocardial Perfusion SPECT Imaging in Patients after Coronary Revascularization. Vascular Disease Prevention, Vol. 5, No. 1, (February 2008), pp. 9-16, ISSN 1567-2700

Georgoulias, P., Tsougos, I., Valotassiou, V., Tzavara, C., Xaplanteris, P., \& Demakopoulos, N. (2010a). Long-term prognostic value of early poststress $(99 \mathrm{~m})$ Tc-tetrofosmin lung uptake during exercise (SPECT) myocardial perfusion imaging. European Journal of Nuclear Medicine and Molecular Imaging, Vol. 37, No. 4, (April 2010), pp. 789-798, ISSN 1619-7070

Georgoulias, P., Valotassiou, V., Tsougos, I., \& Demakopoulos, N. (2010b). Myocardial Perfusion SPECT Imaging in Patients after Percutaneous Coronary Intervention. Current Cardiology Reviews, Vol. 6, No. 2, (May 2010), pp. 98-103, ISSN 1573-403X

Gill, J.B., Ruddy, T.D., Newell, J.B., Finkelstein, D.M., Strauss, H.W., \& Boucher, C.A. (1987). Prognostic importance of thallium uptake by the lungs during exercise in coronary artery disease. The New England Journal of Medicine, Vol. 317, No. 24, (December 1987), pp. 1486-1489, ISSN 0028-4793

Gioia, G., Milan, E., Giubbini, R., DePace, N., Heo, J., \& Iskandrian, A.S. (1996). Prognostic value of tomographic rest-redistribution thallium 201 imaging in medically treated patients with coronary artery disease and left ventricular dysfunction. Journal of Nuclear Cardiology, Vol. 3, No. 2, (March - April 1996), pp. 150-156, ISSN 1071-3581

Giubbini, R., Campini, R., Milan, E., Zoccarato, O., Orlandi, C., Rossini, P., Giannuzzi, P., La Canna, G., \& Galli, M. (1995). Evaluation of technetium-99m-sestamibi lung uptake: correlation with left ventricular function. Journal of Nuclear Medicine, Vol. 36, No. 1, (January 1995), pp. 58-63, ISSN 0161-5505

Gratz, S., Kempke, B., Kaiser, W., Behr, T.M., Pfestroff, A., \& Höffken, H. (2008). Unexpected 99mTc-tetrofosmin findings during myocardial perfusion scintigraphy: intraindividual comparison with PET/computed tomography. Nuclear Medicine Communications, Vol. 29, No. 11, (November 2008), pp. 963-969, ISSN 0143-3636

Hachamovitch, R., Berman, D.S., Shaw, L.J., Kiat, H., Cohen, I., Cabico, J.A., Friedman, J., \& Diamond G.A. (1998). Incremental prognostic value of myocardial perfusion single photon emission computed tomography for the prediction of cardiac death: differential stratification for risk of cardiac death and myocardial infarction. Circulation, Vol. 97, No. 6, (February 1998), pp. 535-543, ISSN 0009-7322

Hachamovitch, R., Hayes, S., Friedman, J.D., Cohen, I., Shaw, L.J., Germano, G., \& Berman, D.S. (2003). Determinants of risk and its temporal variation in patients with normal stress myocardial perfusion scans: what is the warranty period of a normal scan? 
Journal of the American College of Cardiology, Vol. 41, No. 8, (April 2003), pp. 13291340, ISSN 0735-1097

Hadase, M., Kawasaki, T., Kamitsuji, Y., Sakatani, T., Kamitani, T., Kawasaki, S., \& Sugihara, H. (2003). Incidental detection of skeletal uptake on tetrofosmin cardiac imaging in a patient with multiple myeloma. Clinical Nuclear Medicine, Vol. 28, No. 3, (March 2003), pp. 230-231, ISSN 0363-9762

Heo, J., Cave, V., Wasserleben, V., \& Iskandrian, A.S. (1994). Planar and tomographic imaging with technetium 99m-labeled tetrofosmin: correlation with thallium 201 and coronary angiography. Journal of Nuclear Cardiology, Vol. 1, No. 4, (July August 1994), pp. 317-324, ISSN 1071-3581

Hesse, B., Tägil, K., Cuocolo, A., Anagnostopoulos, C., Bardies, M., Bax, J., Bengel, F., Busemann Sokole, E., Davies, G., Dondi, M., Edenbrandt, L., Franken, P., Kjaer, A., Knuuti, J., Lassmann, M., Ljungberg, M., Marcassa, C., Marie, P.Y., McKiddie, F., O'Connor, M., Prvulovich, E., Underwood, R., \& van Eck-Smit, B. (2005). EANM/ESC procedural guidelines for myocardial perfusion imaging in nuclear cardiology. European Journal of Nuclear Medicine and Molecular Imaging, Vol.32, No.7, (July 2005), pp. 855-897, ISSN 1619-7070

Homma, S., Kaul, S., \& Boucher, C.A. (1987). Correlates of lung/heart ratio of thallium-201 in coronary artery disease. Journal of Nuclear Medicine, Vol. 28, No. 10, (October 1987), pp. 1531-1535, ISSN 0161-5505

Hurwitz, G.A., O'Donoghue, J.P., Powe, J.E., Gravelle, D.R., MacDonald, A.C., \& Finnie, K.J. (1992). Pulmonary thallium-201 uptake following dipyridamole-exercise combination compared with single modality stress testing. The American Journal of Cardiology, Vol. 69, No. 4, (February 1992), pp. 320-326, ISSN 0002-9149

Hurwitz, G.A., Fox, S.P., Driedger, A.A., Willems, C., \& Powe, J.E. (1993). Pulmonary uptake of sestamibi on early post-stress images: angiographic relationships, incidence and kinetics. Nuclear Medicine Communications, Vol. 14, No. 1, (January 1993), pp. 15-22, ISSN 0143-3636

Hurwitz, G.A., Blais, M., Powe, J.E., \& Champagne, C.L. (1996). Stress/injection protocols for myocardial scintigraphy with 99Tcm-sestamibi compared with 201Tl: implications of early post-stress kinetics. Nuclear Medicine Communications, Vol. 17, No. 5, (May 1996), pp. 400-409, ISSN 0143-3636

Hurwitz, G.A., Ghali, S.K., Husni, M., Slomka, P.J., Mattar, A.G., Reid, R.H., \& Lefcoe, N.M. (1998). Pulmonary uptake of technetium-99m-sestamibi induced by dipyridamolebased stress or exercise. Journal of Nuclear Medicine, Vol. 39, No. 2, (February 1998), pp. 339-345, ISSN 0161-5505

Hurwitz, G.A. (2000). Increased extra-cardiac background uptake on immediate and delayed post-stress images with 99Tcm sestamibi: determinants, independence, and significance of counts in lung, abdomen and myocardium. Nuclear Medicine Communications, Vol. 21, No. 10, (October 2000), pp. 887-895, ISSN 0143-3636

Iskander, S. \& Iskandrian, A.E. (1998). Risk assessment using single-photon emission computed tomographic technetium-99m sestamibi imaging. Journal of the American College of Cardiology, Vol. 32, No. 1, (July 1998), pp. 57-62, ISSN 0735-1097

Iskandrian, A.S., Chae, S.C., Heo, J., Stanberry, C.D., Wasserleben, V., \& Cave V. (1993). Independent and incremental prognostic value of exercise single-photon emission 
computed tomographic (SPECT) thallium imaging in coronary artery disease. Journal of the American College of Cardiology, Vol. 22, No. 3, (September 1993), pp. 665-670, ISSN 0735-1097

Jain, D., Wackers, F.J., Mattera, J., McMahon, M., Sinusas, A.J., \& Zaret, B.L. (1993). Biokinetics of technetium-99m-tetrofosmin: myocardial perfusion imaging agent: implications for a one-day imaging protocol. Journal of Nuclear Medicine, Vol. 34, No. 8, (August 1993), pp. 1254-1259, ISSN 0161-5505

Jain, D., Thompson, B., Wackers, F.J., \& Zaret, B.L. (1997). Relevance of increased lung thallium uptake on stress imaging in patients with unstable angina and non-Q wave myocardial infarction: results of the Thrombolysis in Myocardial Infarction (TIMI)-IIIB Study. Journal of the American College of Cardiology, Vol. 30, No. 2, (August 1997), pp. 421-429, ISSN 0735-1097

Johnson, L.L., Verdesca, S.A., Aude, W.Y., Xavier, R.C., Nott, L.T., Campanella, M.W., \& Germano, G. (1997). Postischemic stunning can affect left ventricular ejection fraction and regional wall motion on post-stress gated sestamibi tomograms. Journal of the American College of Cardiology, Vol. 30, No. 7, (December 1997), pp. 1641-1648, ISSN 0735-1097

Kannan, S., Ravi Kumar, A.S., \& Griffiths, M. (2007). Incidental finding of thyroid uptake of tc-99m tetrofosmin on a myocardial perfusion scan. Clinical Nuclear Medicine, Vol. 32, No. 1, (January 2007), pp. 73-75, ISSN 0363-9762

Kapur, A., Latus, K.A., Davies, G., Dhawan, R.T., Eastick, S., Jarritt, P.H., Roussakis, G., Young, M.C., Anagnostopoulos, C., Bomanji, J., Costa, D.C., Pennell, D.J., Prvulovich, E.M., Ell, P.J., \& Underwood, S.R. (2002). A comparison of three radionuclide myocardial perfusion tracers in clinical practice: the ROBUST study. European Journal of Nuclear Medicine and Molecular Imaging, Vol.29, No.12, (December 2002), pp. 1608-1616, ISSN 1619-7070

Kaul, S., Finkelstein, D.M., Homma, S., Leavitt, M., Okada, R.D., \& Boucher, C.A. (1988). Superiority of quantitative exercise thallium-201 variables in determining longterm prognosis in ambulatory patients with chest pain: a comparison with cardiac catheterization. Journal of the American College of Cardiology, Vol. 12, No. 1, (July 1998), pp. 25-34, ISSN 0735-1097

Khairallah, F.S., Joyce, J.M., Myers, D.T., \& Organist, M. (2002). Detection of breast carcinoma in a man on dual-isotope Tl-201 and Tc-99m Myoview myocardial perfusion imaging. Clinical Nuclear Medicine, Vol. 27, No. 10, (October 2002), pp. 743-744, ISSN 0363-9762

Kim, S.J., Kim, I.J., \& Kim, Y.K. (2002). Tc-99m MIBI, Tc-99m tetrofosmin, and Tc-99m (V) DMSA accumulation in recurrent malignant thymoma. Clinical Nuclear Medicine, Vol. 27, No. 1, (January 2002), pp. 30-33, ISSN 0363-9762

Kinuya, S., Li, X.F., Yokoyama, K., Mori, H., Shiba, K., Watanabe, N., Shuke, N., Bunko, H., Michigishi, T., \& Tonami, N. (2003). Reduction of 99mTc-sestamibi and 99mTctetrofosmin uptake in MRP-expressing breast cancer cells under hypoxic conditions is independent of MRP function. European Journal of Nuclear Medicine and Molecular Imaging, Vol. 30, No. 11, (November 2003), pp. 1529-1531, ISSN 1619-7070

Kotsalou, I., Georgoulias, P., Fourlis, S., Zoumboulidis, A., Giaslakiotis, K., Androulaki, A., Chronopoulos, P., \& Dimakopoulos, N. (2008). Incidental pathologic 
extracardiac uptake of $99 \mathrm{mTc}$-tetrofosmin in myocardial perfusion imaging. Hellenic Journal of Nuclear Medicine, Vol. 11, No. 1 (January - April 2008), pp. 4345, ISSN 1790-5427

Krawczynska, E.G., Alazraki, N.P., Karatela, R., Jones, M.E., Cooke, C.D., Garcia, E.V., \& Weintraub, W.S. (1997). Prognosis in patients with left ventricular apical aneurysm diagnosed by thallium-201 or Tc-99m sestamibi SPECT images. The American Journal of Cardiology, Vol. 79, No. 4, (February 1997), pp. 406-411, ISSN 0002-9149

Kurata, C., Tawarahara, K., Taguchi, T., Sakata, K., Yamazaki, N., \& Naitoh, Y. (1991). Lung thallium-201 uptake during exercise emission computed tomography. Journal of Nuclear Medicine, Vol. 32, No. 3, (March 1991), pp. 417-423, ISSN 01615505

Ladenheim, M.L., Pollock, B.H., Rozanski, A., Berman, D.S., Staniloff, H.M., Forrester, J.S., \& Diamond, G.A. (1986). Extent and severity of myocardial hypoperfusion as predictors of prognosis in patients with suspected coronary artery disease. Journal of the American College of Cardiology, Vol. 7, No. 3, (March 1986), pp. 464-471, ISSN 0735-1097

Leslie, W.D., Tully, S.A., Yogendran, M.S., Ward, L.M., Nour, K.A., \& Metge, C.J. (2005). Prognostic value of lung sestamibi uptake in myocardial perfusion imaging of patients with known or suspected coronary artery disease. Journal of the American College of Cardiology, Vol. 45, No. 10, (May 2005), pp. 1676-1682, ISSN 0735-1097

Li, Q.S., Solot, G., Frank, T.L., Wagner, H.N. Jr, \& Becker, L.C. (1990). Myocardial redistribution of technetium-99m-methoxyisobutyl isonitrile (SESTAMIBI). Journal of Nuclear Medicine, Vol. 31, No. 6, (June 1990), pp. 1069-1076, ISSN 0161-5505

Liu, P., Kiess, M., Okada, R.D., Strauss, H.W., Block, P.C., Pohost, G.M., \& Boucher, C.A. (1985). Increased thallium lung uptake after exercise in isolated left anterior descending coronary artery disease. The American Journal of Cardiology, Vol. 55, No. 13 Pt 1, (June 1985), pp. 1469-1473, ISSN 0002-9149

Machecourt, J., Longère, P., Fagret, D., Vanzetto, G., Wolf, J.E., Polidori, C., Comet, M., \& Denis, B. (1994). Prognostic value of thallium-201 single-photon emission computed tomographic myocardial perfusion imaging according to extent of myocardial defect. Study in 1,926 patients with follow-up at 33 months. Journal of the American College of Cardiology, Vol. 23, No. 5, (April 1994), pp. 1096-1106, ISSN 0735-1097

Mahmood, S., Buscombe, J.R., \& Ell, P.J. (1992). The use of thallium-201 lung/heart ratios. European Journal of Nuclear Medicine, Vol. 19, No. 9, (1992), pp. 807-814, ISSN 03406997

Marcassa, C., Galli, M., Baroffio, C., Eleuteri, E., Campini, R., \& Giannuzzi, P. (2000). Independent and incremental prognostic value of (201)Tl lung uptake at rest in patients with severe postischemic left ventricular dysfunction. Circulation, Vol. 102, No. 15, (October 2000), pp. 1795-1801, ISSN 0009-7322

Marie, P.Y., Danchin, N., Durand, J.F., Feldmann, L., Grentzinger, A., Olivier, P., Karcher, G., Juillière, Y., Virion, J.M., Beurrier, D., Cherrier, F., \& Bertrand, A. (1995). Longterm prediction of major ischemic events by exercise thallium-201 single-photon emission computed tomography. Incremental prognostic value compared with 
clinical, exercise testing, catheterization and radionuclide angiographic data. Journal of the American College of Cardiology, Vol. 26, No. 4, (October 1995), pp. 879886, ISSN 0735-1097

Morel, O., Pézard, P., Furber, A., Le Jeune, J.J., Vielle, B., Denizot, B., \& Jallet, P. (1999). Thallium-201 right lung/heart ratio during exercise in patients with coronary artery disease: relation to thallium-201 myocardial single-photon emission tomography, rest and exercise left ventricular function and coronary angiography. European Journal of Nuclear Medicine, Vol. 26, No. 6, (June 1999), pp. 640-646, ISSN 0340-6997

Münch, G., Neverve, J., Matsunari, I., Schröter, G., \& Schwaiger, M. (1997). Myocardial technetium-99m-tetrofosmin and technetium-99m-sestamibi kinetics in normal subjects and patients with coronary artery disease. Journal of Nuclear Medicine, Vol. 38, No. 3, (March 1997), pp. 428-432, ISSN 0161-5505

Nakajima, K., Taki, J., Shuke, N., Bunko, H., Takata, S., \& Hisada K. (1993). Myocardial perfusion imaging and dynamic analysis with technetium-99m tetrofosmin. Journal of Nuclear Medicine, Vol. 34, No. 9, (September 1993), pp. 1478-1484, ISSN 0161-5505

Okajima, T., Ueshima, K., Nishiyama, O., Ogawa, M., Ohuchi, M., Saitoh, M., \& Hiramori, K. (2004a). Relationship between lung-to-heart uptake ratio of technetium-99mtetrofosmin during exercise myocardial single photon emission computed tomographic imaging and the number of diseased coronary arteries in patients with effort angina pectoris without myocardial infarction. Journal of Cardiology, Vol. 43, No. 4, (April 2004), pp. 165-171, ISSN 0914-5087

Okajima, T., Ueshima, K., Nishiyama, O., Ogawa, M., Aisaka, M., Saito, M., Masahiro, K., Muranaka, K., Nagamine, M., \& Hiramori, K. (2004b). A case of recurrent breast cancer detected by Tc-99m tetrofosmin myocardial scintigraphy. Clinical Nuclear Medicine, Vol. 29, No. 9, (September 2004), pp. 597, ISSN 0363-9762

Oller, J.D., Gómez, J.D., Kortazar, J.F., García, J.D., Navarro, A.A., Albertino, R.J., Díaz, J.J., Llorente, J.A., Andreu, M.N., Arcas, R.F., Medina, T., \& Vázquez, R.S. (2001). Scapular hibernoma fortuitously discovered on myocardial perfusion imaging through Tc-99m tetrofosmin. Clinical Nuclear Medicine, Vol. 26, No. 1, (January 2001), pp. 69-70, ISSN 0363-9762

Patel, G.M., Hauser, T.H., Parker, J.A., Pinto, D.S., Sanders, G.P., Aepfelbacher, F.C., Koutkia, P., \& Danias, P.G. (2004). Quantitative relationship of stress Tc-99m sestamibi lung uptake with resting Tl-201 lung uptake and with indices of left ventricular dysfunction and coronary artery disease. Journal of Nuclear Cardiology, Vol. 11, No. 4, (July - August 2004), pp. 408-413, ISSN 1071-3581

Rebollo Aguirre, A.C., Jiménez-Hoyuela, J.M., Fernández Aguirre, C., \& Mestre Reoyo, G.I. (2003). Finding a thymoma in a 99mTc-Tetrofosmin myocardial perfusion imaging. Revista Española de Medicina Nuclear, Vol. 22, No. 2, (March - April 2003), pp. 107, ISSN 0212-6982

Romanens, M., Grädel, C., Saner, H., \& Pfisterer, M. (2001). Comparison of 99mTc-sestamibi lung/heart ratio, transient ischaemic dilation and perfusion defect size for the identification of severe and extensive coronary artery disease. European Journal of Nuclear Medicine, Vol. 28, No. 7, (July 2001), pp. 907-910, ISSN 0340-6997 


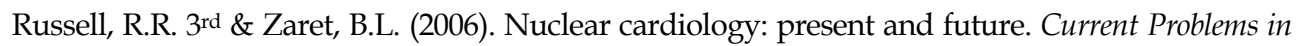
Cardiology, Vol. 31, No. 9, (September 2006), pp. 557-629, ISSN 0146-2806

Saha, M., Farrand, T.F., \& Brown, K.A. (1994). Lung uptake of technetium 99m sestamibi: relation to clinical, exercise, hemodynamic, and left ventricular function variables. Journal of Nuclear Cardiology, Vol. 1, No. 1, (January 1994), pp. 52-56, ISSN 1071-3581

Sarda, L., Fuchs, L., Lebtahi, R., Faraggi, M., Delahaye, N., Hvass, U., \& Le Guludec, D. (2001). Prognostic value of $201 \mathrm{Tl}$ myocardial scintigraphy after coronary artery bypass grafting. Nuclear Medicine Communications, Vol. 22, No. 2, (February 2001), pp. 189-196, ISSN 0143-3636

Satra, M., Samara, M., Wosniak, G., Tzavara, C., Kontos, A., Valotassiou, V., Vamvakopoulos, N.K., Tsougos, I., Aleporou-Marinou, V., Patrinos, G.P., Kollia, P., \& Georgoulias, P. (2011). Sequence variations in the FII, FV, F13A1, FGB, and PAI-1 genes are associated with differences in myocardial perfusion. Pharmacogenomics, Vol. 12, No. 2, (February 2011), pp. 195-203, ISSN 1462-2416

Schinkel, A.F., Elhendy, A., Biagini, E., van Domburg, R.T., Valkema, R., Rizello, V., Pedone, C., Simoons, M., Bax, J.J., \& Poldermans, D. (2005). Prognostic stratification using dobutamine stress 99mTc-tetrofosmin myocardial perfusion SPECT in elderly patients unable to perform exercise testing. Journal of Nuclear Medicine, Vol. 46, No. 1, (January 2005), pp. 12-18, ISSN 0161-5505

Sciagrà, R., Passeri, A., Poggesi, L., Matteini, M., Pellegri, M., \& Paglianiti, I. (1998). Detection of malignant thymoma during myocardial perfusion tomography with Tc-99m sestamibi: potential implications for tumor evaluation and staging. Clinical Nuclear Medicine, Vol. 23, No. 12, (December 1998), pp. 842-843, ISSN 0363-9762

Sharir, T., Germano, G., Kavanagh, P.B., Lai, S., Cohen, I., Lewin, H.C., Friedman, J.D., Zellweger, M.J., \& Berman, D.S. (1999). Incremental prognostic value of post-stress left ventricular ejection fraction and volume by gated myocardial perfusion single photon emission computed tomography. Circulation, Vol. 100, No. 10, (September 1999), pp. 1035-1042, ISSN 0009-7322

Sharir, T., Germano, G., Kang, X., Lewin, H.C., Miranda, R., Cohen, I., Agafitei, R.D., Friedman, J.D., \& Berman, D.S. (2001). Prediction of myocardial infarction versus cardiac death by gated myocardial perfusion SPECT: risk stratification by the amount of stress-induced ischemia and the poststress ejection fraction. Journal of Nuclear Medicine, Vol. 42, No. 6, (June 2001), pp. 831-837, ISSN 0161-5505

Shaw, L.J., Hendel, R., Borges-Neto, S., Lauer, M.S., Alazraki, N., Burnette, J., Krawczynska, E., Cerqueira, M., \& Maddahi, J. (2003). Prognostic value of normal exercise and adenosine $(99 \mathrm{~m}) \mathrm{Tc}$-tetrofosmin SPECT imaging: results from the multicenter registry of 4,728 patients. Journal of Nuclear Medicine, Vol. 44, No. 2, (February 2003), pp. 134-139, ISSN 0161-5505

Shih, W.J., Kiefer, V., Gross, K., Wierzbinski, B., Collins, J., Pulmano, C., \& Ryo, Y.U. (2002). Intrathoracic and intra-abdominal Tl-201 abnormalities seen on rotating raw cine data on dual radionuclide myocardial perfusion and gated SPECT. Clinical Nuclear Medicine, Vol. 27, No. 1, (January 2002), pp. 40-44, ISSN 0363-9762 
Shih, W.J., McFarland, K.A., Kiefer, V., \& Wierzbinski, B. (2005). Illustrations of abdominal abnormalities on $99 \mathrm{mTc}$ tetrofosmin gated cardiac SPECT. Nuclear Medicine Communications, Vol. 26, No. 2, (February 2005), pp. 119-127, ISSN 0143-3636

Sridhara, B.S., Braat, S., Rigo, P., Itti, R., Cload, P., \& Lahiri, A. (1993). Comparison of myocardial perfusion imaging with technetium-99m tetrofosmin versus thallium201 in coronary artery disease. The American Journal of Cardiology, Vol. 72, No. 14, (November 1993), pp. 1015-1019, ISSN 0002-9149

Sükan, A., Yapar, Z., Sahin, B., Kara, O., Fuat Yapar, A., Cetiner, S., \& Kibar, M. (2004). $99 \mathrm{mTc}$ tetrofosmin scintigraphy in acute leukaemia: the relationship between marrow uptake of tetrofosmin and P-glycoprotein and chemotherapy response. Nuclear Medicine Communications, Vol. 25, No. 8, (August 2004), pp. 777-785, ISSN 0143-3636

Tanigaki, K., Kobayashi, H., Momose, M., Takara, A., Kanaya, S., Terada, S., Ikegami, H., \& Kusakabe, K. (1998). Clinical utility of pulmonary 99mTc-Tetrofosmin uptake measurement by the exercise myocardial scintigraphy in patients with ischemic heart disease. Kaku Igaku, Vol. 35, No. 4, (April 1998), pp. 189-195, ISSN 00227854

Torreggiani, W., Brenner, C., \& Hogan, B. (1999). Incidental diagnosis of breast carcinoma following technetium $99 \mathrm{~m}$ tetrofosmin (myoview) scintigraphy for evaluation of ischaemic heart disease. Irish Medical Journal, Vol. 92, No. 7, (November - December 1999), pp. 437-438, ISSN 0332-3102

Tsou, S.S., Sun, S.S., Kao, A., Lin, C.C., \& Lee, C.C. (2002). Exercise and rest technetium-99mtetrofosmin lung uptake: correlation with left ventricular ejection fraction in patients with coronary artery disease. Japanese Heart Journal, Vol. 43, No. 5, (September 2002), pp. 512-522, ISSN 0021-4868

Underwood, S.R., Anagnostopoulos, C., Cerqueira, M., Ell, P.J., Flint, E.J., Harbinson, M., Kelion, A.D., Al-Mohammad, A., Prvulovich, E.M., Shaw, L.J., \& Tweddel, A.C. (2004). Myocardial perfusion scintigraphy: the evidence. European Journal of Nuclear Medicine and Molecular Imaging, Vol. 31, No. 2, (February 2004), pp. 261-291, ISSN 1619-7070

Valotassiou, V., Demakopoulos, N., Tzavara, C., Giannakou, S., Tsougos, I., Orfanakis, A., \& Georgoulias, P. (2009). Incremental prognostic value of Tc-99m tetrofosmin early post-stress lung uptake during gated-SPECT myocardial perfusion imaging. European Journal of Nuclear Medicine and Molecular Imaging, Vol. 36, Suppl. 2, (September 2009), pp. 281-496, ISSN 1619-7070.

Vijayakumar, V., Soloff, E., \& Rahman, A.M. (2004). Increased tc-99m tetrofosmin uptake in a mediastinal tumor during myocardial perfusion imaging. Clinical Nuclear Medicine, Vol. 29, No. 6, (June 2004), pp. 390-391, ISSN 0363-9762

Vijayakumar, V., Gupta, R., \& Rahman, A. (2005). Pathologic extracardiac uptake of Tc$99 \mathrm{~m}$ tetrofosmin identified in the chest during myocardial perfusion imaging. Journal of Nuclear Cardiology, Vol. 12, No. 4, (July - August 2005), pp. 473-475, ISSN 1071-3581

Weiss, A.T., Berman, D.S., Lew, A.S., Nielsen, J., Potkin, B., Swan, H.J., Waxman, A., \& Maddahi, J. (1987). Transient ischemic dilation of the left ventricle on stress thallium-201 scintigraphy: a marker of severe and extensive coronary artery 
disease. Journal of the American College of Cardiology, Vol. 9, No. 4, (April 1987), pp. 752-759, ISSN 0735-1097

Wu, Y.W., Yen, R.F., Lee, C.M., Ho, Y.L., Chou, N.K., Wang, S.S., \& Huang, P.J. (2005). Diagnostic and prognostic value of dobutamine thallium-201 single-photon emission computed tomography after heart transplantation. The Journal of Heart and Lung Transplantation, Vol. 24, No. 5, (May 2005), pp. 544-550, ISSN 1053-2498

Yi, A. \& Jacobs, M. (2004). Skeletal tetrofosmin uptake in a patient undergoing myocardial perfusion imaging with a subsequent diagnosis of multiple myeloma. Clinical Nuclear Medicine, Vol. 29, No. 5, (May 2004), pp. 327-328, ISSN 0363-9762 


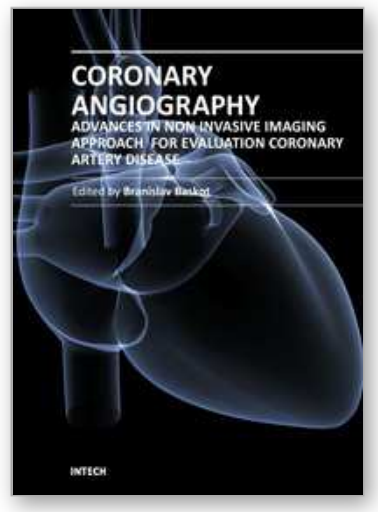

\author{
Coronary Angiography - Advances in Noninvasive Imaging \\ Approach for Evaluation of Coronary Artery Disease
}

Edited by Prof. Baskot Branislav

ISBN 978-953-307-675-1

Hard cover, 414 pages

Publisher InTech

Published online 15, September, 2011

Published in print edition September, 2011

In the intervening 10 years tremendous advances in the field of cardiac computed tomography have occurred. We now can legitimately claim that computed tomography angiography (CTA) of the coronary arteries is available. In the evaluation of patients with suspected coronary artery disease (CAD), many guidelines today consider CTA an alternative to stress testing. The use of CTA in primary prevention patients is more controversial in considering diagnostic test interpretation in populations with a low prevalence to disease. However the nuclear technique most frequently used by cardiologists is myocardial perfusion imaging (MPI). The combination of a nuclear camera with CTA allows for the attainment of coronary anatomic, cardiac function and MPI from one piece of equipment. PET/SPECT cameras can now assess perfusion, function, and metabolism. Assessing cardiac viability is now fairly routine with these enhancements to cardiac imaging. This issue is full of important information that every cardiologist needs to now.

\title{
How to reference
}

In order to correctly reference this scholarly work, feel free to copy and paste the following:

Panagiotis Georgoulias, Varvara Valotassiou, loannis Tsougos, George Angelidis and Nikolaos Demakopoulos (2011). Clinical Significance of Tetrofosm in Extracardiac Uptake During Myocardial Perfusion Imaging, Coronary Angiography - Advances in Noninvasive Imaging Approach for Evaluation of Coronary Artery Disease, Prof. Baskot Branislav (Ed.), ISBN: 978-953-307-675-1, InTech, Available from: http://www.intechopen.com/books/coronary-angiography-advances-in-noninvasive-imaging-approach-forevaluation-of-coronary-artery-disease/clinical-significance-of-tetrofosm-in-extracardiac-uptake-duringmyocardial-perfusion-imaging

\section{INTECH}

open science | open minds

\author{
InTech Europe \\ University Campus STeP Ri \\ Slavka Krautzeka 83/A \\ 51000 Rijeka, Croatia \\ Phone: +385 (51) 770447 \\ Fax: +385 (51) 686166 \\ www.intechopen.com
}

\author{
InTech China \\ Unit 405, Office Block, Hotel Equatorial Shanghai \\ No.65, Yan An Road (West), Shanghai, 200040, China \\ 中国上海市延安西路65号上海国际贵都大饭店办公楼405单元 \\ Phone: +86-21-62489820 \\ Fax: $+86-21-62489821$
}


(C) 2011 The Author(s). Licensee IntechOpen. This chapter is distributed under the terms of the Creative Commons Attribution-NonCommercialShareAlike-3.0 License, which permits use, distribution and reproduction for non-commercial purposes, provided the original is properly cited and derivative works building on this content are distributed under the same license. 